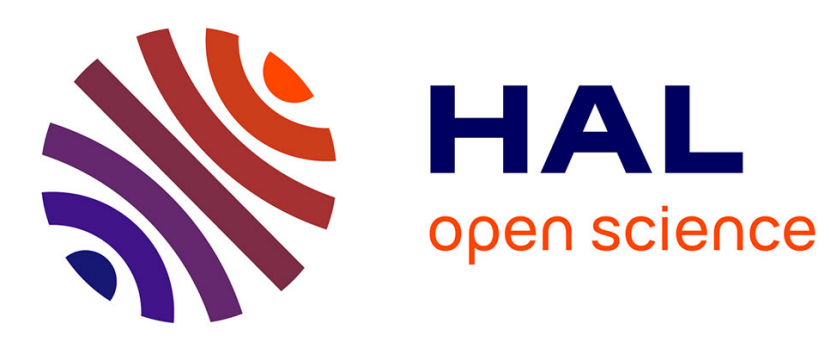

\title{
Influence of temperature, UV-light wavelength and intensity on polypropylene photothermal oxidation
} Alexandre Francois-Heude, Emmanuel Richaud, Eric Desnoux, Xavier Colin

\section{To cite this version:}

Alexandre Francois-Heude, Emmanuel Richaud, Eric Desnoux, Xavier Colin. Influence of temperature, UV-light wavelength and intensity on polypropylene photothermal oxidation. Polymer Degradation and Stability, 2014, 100 (1), pp.10-20. 10.1016/j.polymdegradstab.2013.12.038 . hal-00980353

\section{HAL Id: hal-00980353 https://hal.science/hal-00980353}

Submitted on 4 Jul 2014

HAL is a multi-disciplinary open access archive for the deposit and dissemination of scientific research documents, whether they are published or not. The documents may come from teaching and research institutions in France or abroad, or from public or private research centers.
L'archive ouverte pluridisciplinaire HAL, est destinée au dépôt et à la diffusion de documents scientifiques de niveau recherche, publiés ou non, émanant des établissements d'enseignement et de recherche français ou étrangers, des laboratoires publics ou privés. 


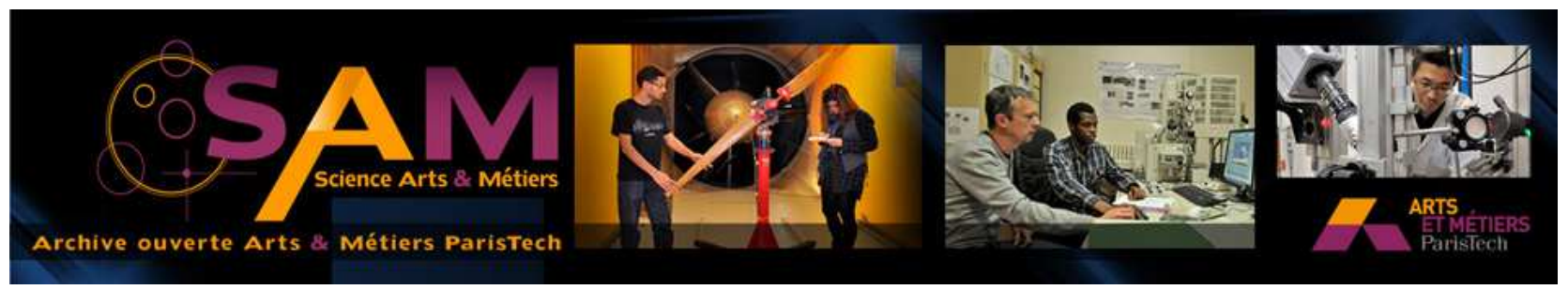

Science Arts \& Métiers (SAM)

is an open access repository that collects the work of Arts et Métiers ParisTech researchers and makes it freely available over the web where possible.

This is an author-deposited version published in: http://sam.ensam.eu

Handle ID: .http://hdl.handle.net/10985/7978

\section{To cite this version :}

Alexandre FRANCOIS-HEUDE, Emmanuel RICHAUD, Eric DESNOUX, Xavier COLIN - Influence of temperature, UV-light wavelength and intensity on polypropylene photothermal oxidation Polymer Degradation and Stability - Vol. 100, n¹, p.10-20 - 2014 


\title{
Influence of temperature, UV-light wavelength and intensity on polypropylene photothermal oxidation
}

\author{
Alexandre François-Heude ${ }^{a, b, *}, E^{2}$ mmanuel Richaud ${ }^{a}$, Eric Desnoux ${ }^{b}$, Xavier Colin $^{a}$ \\ a PIMM Laboratory, CNRS UMR 8006, Arts et Metiers ParisTech, Paris, France \\ ${ }^{b}$ Renault, DETC-A, Guyancourt, France
}

Keywords:

Polypropylene photodegradation

Lifetime prediction

Reciprocity law

Actinometry

Oxidation kinetics

\begin{abstract}
A B S T R A C T
A criterion based on the energy absorbed by photosensitive species was proposed to describe the contribution of UV-light to the initiation of the polypropylene photothermal oxidation whatever the light source. The calculation of this energy was performed using the widely accepted quantum theory. The criterion was then introduced in two different types of analytical models commonly used to describe the combined effects of UV light and temperature on induction time, namely: the reciprocity law and kinetic model. The limitations of both types of analytical models were then investigated: the latter, derived from a realistic mechanistic scheme, was found to be much more relevant than the former, which is presumably valid in a restricted range of light intensities, essentially due to its empirical origin.
\end{abstract}

\section{Introduction}

It is now well known that polypropylene (PP) oxidation depends on both light and temperature in current outdoor aging conditions. The influence of temperature, commonly described with an Arrhenius law, was widely investigated in the case of thermal oxidation, but rarely in the case of photothermal oxidation [1,2]. The quantitative effects of the UV light intensity on the photodegradation were studied for various type of polymers including coatings [3,4], polycarbonates [5-7], poly(vinyl chloride) [8] and also polyolefins [2,9-14]. Most of these studies were based on empirical reciprocity laws (usually applied to the induction period or time to embrittlement), which have been recently reviewed by Martin et al. for a wide range of materials including polymeric ones [15]. For polypropylene, the dependence of the induction period with the UV-light irradiance was $I^{n}$ with $n=-1 / 2$ for unstabilized PP using filtered high pressure mercury [12] or fluorescent lamps [13]. Both references also reported values of $n$ up to $-\mathbf{1}$ for stabilized PP depending on the type of stabilizer and its concentration $[12,13]$. However, Philippart [11] also found a dependence of the induction time with the inverse of irradiance for only weakly

\footnotetext{
* Corresponding author. PIMM Laboratory, CNRS UMR 8006, Arts et Metiers ParisTech, Paris, France. Tel./fax: +331442464 13/+33144246382.

E-mail address: Alexandre.FRANCOIS-HEUDE@ensam.eu (A. François-Heude).
}

stabilized PP using filtered medium pressure mercury lamps. The steady-state oxidation rate was found to vary with the square root of the irradiance in agreement with the analytical solution of the basic auto-oxidation scheme $[9,12,16]$ Cumulated exposure energy is usually chosen as the key variable to follow the polymer degradation because it is very convenient for natural weathering where the exposure parameters undergo temporary fluctuations such as daily/seasonal temperature or UV light variations.

Nonetheless, not only the light intensity but also its wavelength and, in particular, the light source spectral distribution must be considered since specific spectral sensitivities were evidenced for various polymers (see reviews $[17,18]$ ), including polypropylene [19-21]. This notion of polymer light sensitivity can be correlated with the first law of photochemistry attesting that only absorbed quanta can initiate reactions, if they have a sufficient energy to dissociate a chemical bond $[22,23]$.

As an example, the initiation rate by hydroperoxides photolysis can be written as:

$$
v_{\mathrm{POOH}}=\frac{\mathrm{d}[\mathrm{POOH}]}{\mathrm{d} t}=-\Phi(\lambda)_{\mathrm{POOH}} \times I_{\mathrm{absv}}
$$

with $[\mathrm{POOH}]$ the concentration in hydroperoxides (in $\mathrm{mol} \mathrm{L}^{-1}$ ),

$\Phi(\lambda)_{\mathrm{POOH}}$ the quantum yield of photolysis (in mol Einstein ${ }^{-1}$, dimensionless) and $I_{\text {abs.v }}$ the volumic absorbed energy (in Einstein $\mathrm{L}^{-1} \mathrm{~s}^{-1}$ ) 
The quantum yield -or quantum efficiency- $\Phi$ represents the probability that a quantum absorbed by a molecule causes its decomposition. The quantum yield is defined as:

$\Phi=\frac{\text { Number of molecules } X \text { having reacted per time unit }}{\text { Number of photons absorbed per time unit }}$

$$
=\frac{d X / d t}{d n_{\mathrm{p}} / d t}=\frac{d[X] / d t}{I_{\mathrm{absv}}}
$$

with $[X]$ the concentration of molecule $X\left(\right.$ in $\mathrm{mol} \mathrm{L}^{-1}$ ),

$n_{\mathrm{p}}$ the number of quanta,

and $I_{\text {abs.v }}$ the volumic absorbed energy (in Einstein $\mathrm{L}^{-1} \mathrm{~s}^{-1}$ ).

However, molecules only absorb photons with a quantum of energy satisfying the authorized electronic transitions, i.e. if the incident photon presents a quantum of energy equal to the difference between a vibrational level of the excited state and the ground state. The probability of occurrence of this phenomenon is taken into account through the molar extinction coefficient - or cross section - in the Beer Lambert's law. It is thus necessary to consider a coupling between the emission spectrum of the polychromatic source and the absorption spectra of the different chromophoric species. Martin and Lechner $[24,25]$ proposed a formalism for the light dependence and chose the dose as relevant criterion:

$D=\int_{0}^{t} D_{\mathrm{eff}}(t) d t=\int_{0}^{t} \int_{\lambda_{\min }}^{\lambda_{\max }} E(\lambda)\left(1-e^{-\ln (10)^{*} A(\lambda)}\right) \Phi(\lambda) d \lambda d t$

with $D$ the dose, i.e. the amount of energy absorbed by the chromophoric species during a duration $t$ (in $\mathrm{J} \mathrm{m}^{-2}$ ), $D_{\text {eff }}(t)$ the absorbed irradiance (in $\mathrm{W} \mathrm{m}^{-2}$ ), $\Phi(\lambda)$ the spectral quantum yield, $A(\lambda)$ the absorbance, and $E(\lambda)$ the spectral irradiance (in $\mathrm{W} \mathrm{m}^{-2} \mathrm{~nm}^{-1}$ ).

Such an approach was previously applied for lifetime prediction of coatings [26-28]. Yet, the dose calculation requires the knowledge of the concentration of chromophoric species along the course of degradation. Then, focusing on the dose rate appears to be more convenient. Indeed, the absorbed energy by a photosensitive species (analogous to the dose rate $D_{\text {eff }}(t)$ ) can be explicated locally. As an example, in the case of hydroperoxides, it can be written:

$$
I_{\mathrm{absv}}=\int_{\lambda_{\min }}^{\lambda_{\max }} \frac{\ln (10)}{10} \frac{E(\lambda)}{N_{\mathrm{a}}} \frac{\lambda}{h c} \frac{\varepsilon(\lambda)_{\mathrm{POOH}} \Delta z[\mathrm{POOH}]}{\Delta z} d \lambda
$$

with $E(\lambda)$ the spectral irradiance of the light source including filters (in $\mathrm{W} \mathrm{m}^{-2} \mathrm{~nm}^{-1}$ ),

$N_{\mathrm{a}}$ the Avogadro's constant, $h$ the Planck constant equal to $6.623 \times 10^{-34} \mathrm{~J} \mathrm{~s}$, $c$ the light celerity (in $\mathrm{m} \mathrm{s}^{-1}$ ), $\lambda$ the wavelength (in $\mathrm{m}$ ), $\varepsilon(\lambda)_{\mathrm{POOH}}$ the spectral distribution of the molar extinction coefficient (in $\mathrm{L} \mathrm{mol}^{-1} \mathrm{~cm}^{-1}$ ),

$[\mathrm{POOH}]$ the hydroperoxide concentration (in $\mathrm{mol} \mathrm{L}^{-1}$ ), and $\Delta z$ the sample thickness (in $\mathrm{m}$ ).

In order to suppress the concentration dependence, we decide to calculate the spectral overlap integral (or so-called in a shortened form, overlap function) JPOOH (in Einstein $\mathrm{mol}^{-1} \mathrm{~s}^{-1}$ ) chosen here as the relevant criterion to describe oxidation, and defined as:

$$
J_{\mathrm{POOH}}=\frac{I_{\mathrm{absv}}}{[\mathrm{POOH}]}=\int_{\lambda_{\min }}^{\lambda_{\max }} \frac{\ln (10)}{10} \frac{E(\lambda)}{N_{\mathrm{a}}} \frac{\lambda}{h c} \varepsilon(\lambda)_{\mathrm{POOH}} d \lambda
$$

Provided that the quantum yield is a constant in the whole spectral range - i.e. its spectral distribution can be neglected - the absorbed energy appears as the relevant criterion controlling the oxidation kinetics. Such a hypothesis is not unrealistic considering that the efficient wavelength range is restricted to few decades of nanometers in current photochemical aging conditions (bandwidth of the molar absorptivity multiplied by the bandwidth of the light source, usually filtered below $300 \mathrm{~nm}$ ).

Such an approach was already used by Carlsson and Wiles in order to calculate the quantum yields of ketone [29] - according to Norrish I and II - and hydroperoxide [30] photolysis by an inverse method. In this article, we will start from these theoretical concepts to tentatively explain the oxidation behavior of PP under the combined effects of temperature and UV light regardless the type of the UV light source under consideration.

\section{Experimental part}

\subsection{Materials}

The reference material was an isotactic homo-polypropylene injection molding grade $\left(\mathrm{Mw}=250 \mathrm{~kg} \mathrm{~mol}^{-1}, \mathrm{Mn}=67 \mathrm{~kg} \mathrm{~mol}^{-1}\right.$ ) supplied by Aldrich. Thin films of $80 \mu \mathrm{m}$ and $135 \mu \mathrm{m}$ were processed by compression molding and then purified from their antioxidants in Soxhlet with dichloromethane for $48 \mathrm{~h}$ prior to aging experiments. The polymer was checked to be unstabilized with an Oxidation Induction Time of $27 \pm 3 \mathrm{~min}$ at $140^{\circ} \mathrm{C}$ in a pure oxygen flow. The crystallinity was calculated equal to $45 \pm 3 \mathrm{wt} \%$ from the melting enthalpy measured by DSC in a TA Q1000 device, taking $\Delta H_{\mathrm{m}}^{0}=209 \mathrm{~J} \mathrm{~g}^{-1}$ for crystalline lamellae.

\subsection{Light and/or thermal exposure}

In order to decouple the light effects from the thermal ones, PP films were exposed under different UV light intensities and temperatures, always in dry conditions. Photothermal aging experiments were mostly performed on films of $80 \mu \mathrm{m}$ thickness in a series of SEPAP devices equipped with $80 \mathrm{~W}$ medium pressure arc mercury lamps having a borosilicate filter. To vary the light intensity, the number of lamps was changed from 2 to 4 lamps in a SEPAP 1224 device, and from 6 to 8 lamps in a SEPAP 50-24 device. Both light intensity and emission spectrum were measured using respectively a IL390C radiometer in the $295-415 \mathrm{~nm}$ range and a Avantes spectro-radiometer (AvaSpec 2048x14-USB2, resolution $0.7 \mathrm{~nm}$ ) in the $250-750 \mathrm{~nm}$ range. Temperature was fixed at $45^{\circ} \mathrm{C}, 60^{\circ} \mathrm{C}$ or $80^{\circ} \mathrm{C}$ according to the apparatus specifications and directly monitored on sample surfaces using a thermo-button temperature logger. A photothermal aging test was also performed on films of $135 \mu \mathrm{m}$ thickness in a WeatherO'Meter device (WOM), equipped with a Xenon Lamp and Borosilicate S/S filters. Black Panel(BPT) and chamber ( $\sim$ White Panel Temperature) temperatures were respectively fixed at $70{ }^{\circ} \mathrm{C}$ and $55^{\circ} \mathrm{C}$. The temperature of the sample was found to be intermediary at $64^{\circ} \mathrm{C}$, whereas the irradiance at $340 \mathrm{~nm}$ was measured at $0.46 \mathrm{~W} \mathrm{~m}^{-2} \mathrm{~nm}^{-1}$, without water spraying. The thermal oxidation (in the absence of light) was also investigated in air-ventilated ovens for temperatures ranging from $60^{\circ} \mathrm{C}$ to $140^{\circ} \mathrm{C}$.

\subsection{Spectrophotometry measurements}

The PP oxidation was monitored using the carbonyl peak centered at $1713 \mathrm{~cm}^{-1}$ with a FTIR Nicolet 510 FTIR-spectrophotometer. All optical densities were normalized by the film thickness and a global carbonyl concentration was calculated through the classical Beer-Lambert's law using a molar extinction coefficient of $300 \mathrm{~L} \mathrm{~mol}^{-1} \mathrm{~cm}^{-1}$. 


\section{Results and discussion}

\subsection{Impact of exposure conditions on lifetime}

As shown in Fig. 1, the results were reproducible for all the tests in SEPAP. A great attention was paid to the temperature regulation which was shown to significantly affect the quality of the results. Indeed, when periodically removing the films from UV chambers for monitoring the course of oxidation, a certain time (which depends on the exposure conditions) was required to stabilize the temperature at the sample surface. This is due to the heating induced by the irradiation although minimized in SEPAP devices with low infrared emissions. Thanks to the monitoring of the sample temperature, these durations were subtracted to the global duration spent by samples in the UV chambers to deduce the effective duration at the target temperature.

To describe the effect of light on polypropylene photooxidation, it is conventional to consider as key variable the irradiance between 300 and $400 \mathrm{~nm}$ which roughly applies to the range of PP sensitivity under sunlight - or equivalent artificial light sources - exposure. Considering the irradiances of our tests in WOM and in SEPAP with two lamps (2 UV-lamps) respectively equal to 55 and $38 \mathrm{~W} \mathrm{~m}^{-2}$ (at close temperatures) the oxidation induction time of the former would be lower than the latter, but the opposite trend is observed. The theory previously explained suggests that a fine description and quantification of the efficient energy to trigger oxidation, i.e. the absorbed energy, would explain this phenomenon. Among all the photosensitive species, two were reported to be particularly critical in the case of PP oxidation and thereby considered: hydroperoxides and ketones [29,31].

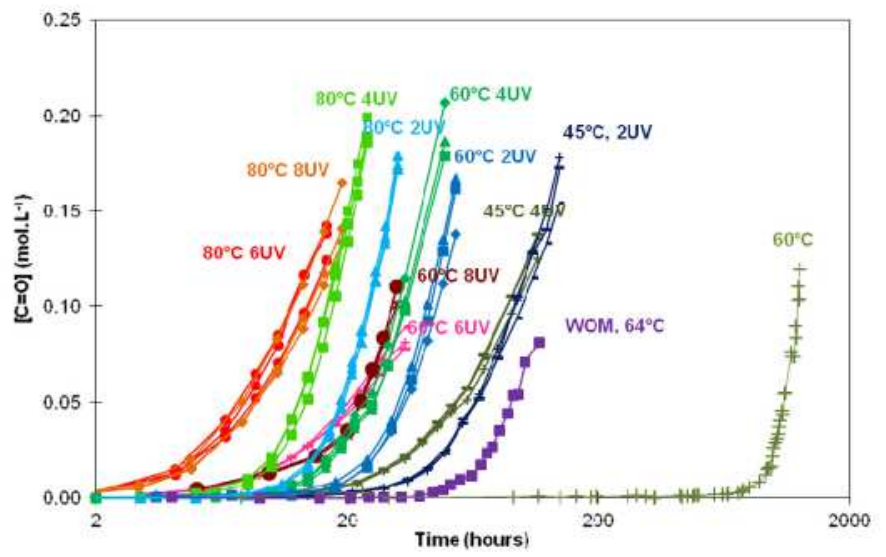

Fig. 1. Change in the carbonyl concentration during thermal (at $60^{\circ} \mathrm{C}$ ) and photothermal oxidation of PP (The temperature and number of UV lamps are indicated for test in SEPAP),

\section{Cross sections of photosensitive species and calculation of the overlap function}

Spectral distribution of the molar extinction coefficient - also called cross section - was compiled from literature for peroxide (Fig. 2) and ketone (Fig. 3) type's model compounds.

Tert-butyl hydroperoxide in hexane solution was chosen as representative of PP hydroperoxides. Its whole spectrum was obtained from two continuous sets of data by different authors in different wavelength ranges $[31,32]$ and compared to those of other compounds of the same family, such as hydrogen peroxide [33], methyl hydroperoxide [34-38], dimethyl peroxide [39] and ditertbutyl peroxide [23,31], mostly in gas phase. Absorption spectra have similar spectral distribution and are rather homothetic with only slight variations depending on the compounds and their

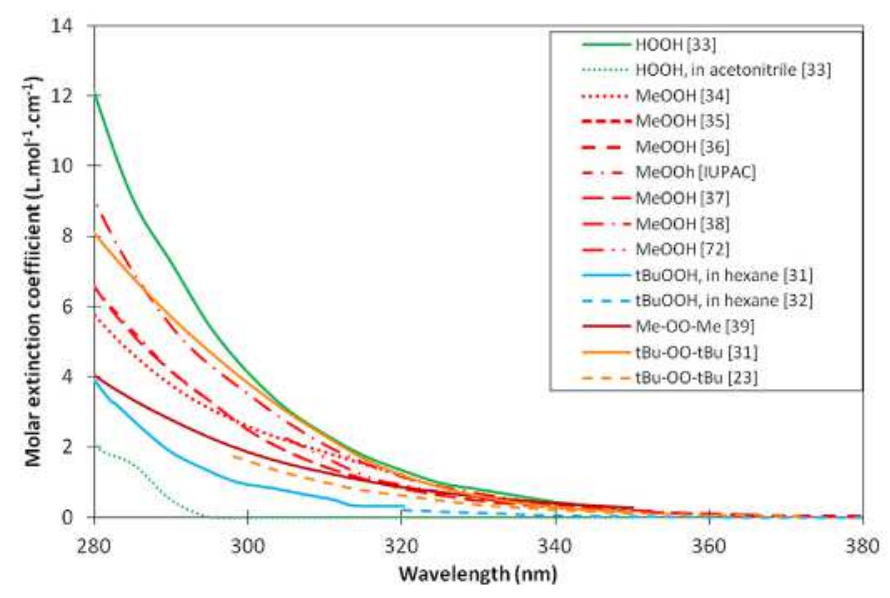

Fig. 2. Absorption cross section spectra for various peroxide compounds including hydrogen peroxide [33], methyl hydroperoxide [34-38,72], tert-butyl hydroperoxide $[31,32]$ (Two sets of data from different authors were required to obtain the molar absorptivity in the whole range of wavelength under consideration), dimethyl peroxide [39] and ditert-butyl peroxide from Carlsson [31] and MicMillan (reported in Ref. [23], p. 443) (colors are available online).

chemical environment. Besides, peroxide type compounds have cross section usually lower than analogous hydroperoxides, except $\mathrm{t}$-BuOOH compared to $\mathrm{tBuOOtBu}$ above $260 \mathrm{~nm}$. Consequently, dialkyl peroxides are neglected here as photosensitive species in comparison with hydroperoxides because these former are assumed in low concentration.

Absorption cross section spectra were reported for various ketones:

(i) 4-methyl-2-pentanone accounting for methyl ketones, which results from the oxidation of methyne units (i.e. tertiary carbon) along PP oxidation [40].

(ii) 2,4-dimethyl-3-pentanone accounting for ketones which results from the oxidation of methylene units (i.e. secondary carbon) [40].

(iii) Various model compounds accounting for ketones on nonbranched chains [33,40-42], such as acetone, butanone and pentanone, some of them being 2-alkanone similar to so-called end-chain ketones in PP.

(iv) Ketones from polyethylene-co-carbon monoxide which is a ketone carried by a non-branched macromolecular chains. The present values are consistent with those previously published by Guillet et al. [43]. Cross sections of poly(ethylene-co-vinyl acetate) or poly(ethylene-comethalcrylic acid) were also measured experimentally and shown that both carbonyl species are considerably less photosensitive than ketones in the investigated wavelength range.

The first two model compounds, i.e. 4-methyl-2-pentanone and 2,4-dimethyl-3-pentanone, were already chosen by Carlsson and Wiles as PP substitutes in solid state [29], and found to be similar in hexane solutions. The spectrum is reported below, but it looks more like that of 4-methyl-2-pentanone than 2,4-dimethyl-3-pentanone in gas phase. Anyway, the former compound is predominant since oxidation is known to occur mainly on tertiary carbons in PP [44]. The Carlsson's spectrum was chosen for this study because it seems rather consistent with all spectra recorded for ketones, but also with data measured on polyethylene-co-carbon monoxide polymer. Moreover, aldehyde spectra also reveal high cross sections, thus indicating that they may also absorb in the wavelength range 


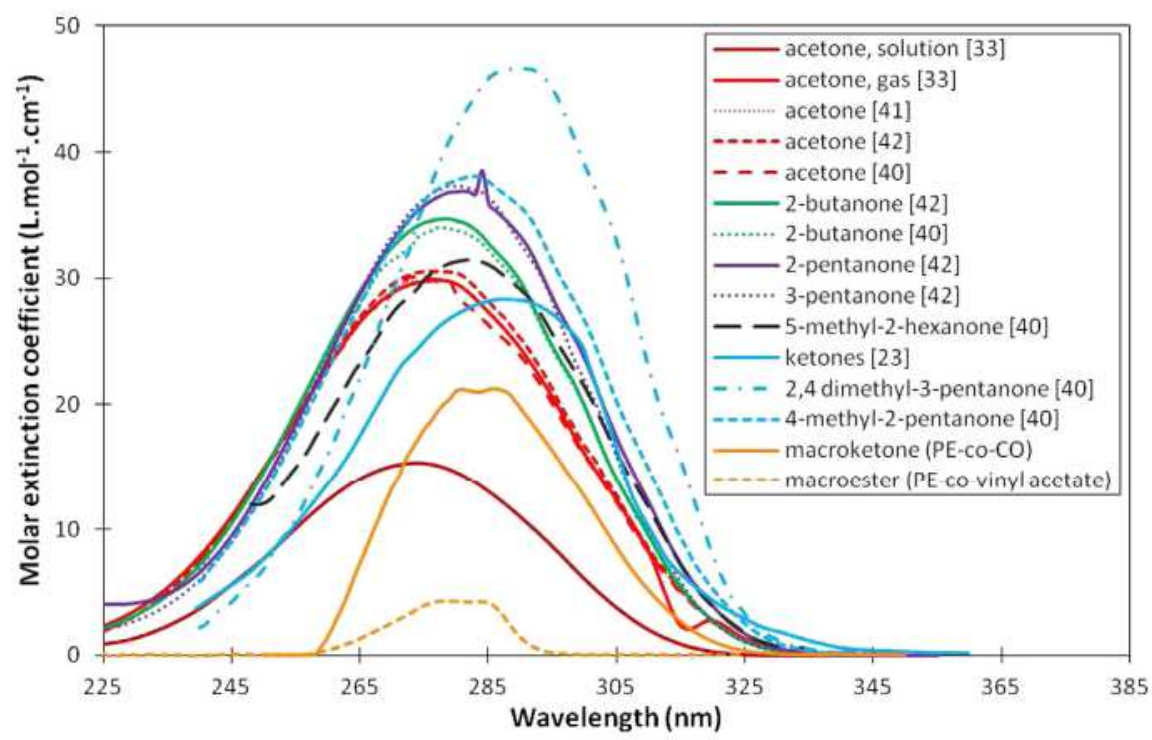

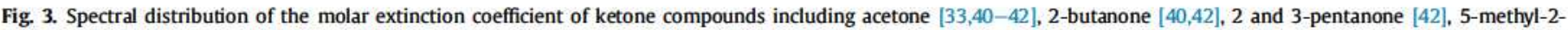

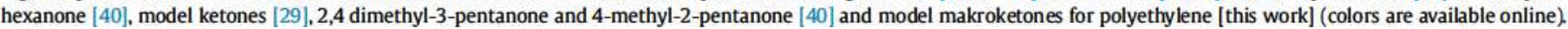

under study, all the more that their absorption maxima are shifted towards higher wavelengths $[42,45,46]$. However, they are neglected due to their presumed low concentrations owing to their high reactivity. In contrast, carboxylic acids and esters are neglected because they are not or very weakly photosensitive to irradiance above $290 \mathrm{~nm}$. As an example, the molar absorptivity of esters is depicted in Fig. 3.

As detailed in introduction, the overlap function $\mathrm{J}_{\text {species }}$ for a given species, is obtained by integrating over the whole wavelength range (here $250-800 \mathrm{~nm}$ ) the product $\mathrm{dJ}_{\text {species }}$ of the radiation source's spectrum with the absorption cross sections spectrum. It thus applies to the area under the curve depicted in Fig. 4. Results are reported in the case of hydroperoxides or ketones as initiating species for an arc mercury lamp (for a SEPAP 12-24 device), a xenon lamp (WOM) and sun as radiation sources. According to the theory developed here, some interesting parallels can be drawn between the spectral distribution of the molar extinction coefficients (Figs. 2 and 3) and the action spectrum on one side, and between the spectral distribution of the absorbed quanta (in Fig. $4 a$ and b) and the activation spectrum of the polymer on the other side. Indeed, the action and activation spectra represent the wavelength dependence of a photoprocess effectiveness and of the extent of degradation (damages) respectively (for further details, refer to the following reviews $[17,18])$. Therefore, they only differ from the spectral distributions of the molar extinction coefficient and absorbed quanta by the spectral distribution of the quantum yield for the involved photoprocess. It turns out that the spectral distribution of the absorbed quanta for a Xenon lamp (or sunlight) is effective in the range $300-360 \mathrm{~nm}$ with a maximum at $315-$ $335 \mathrm{~nm}$. This result is in full agreement with the activation spectra of the literature reporting quanta activity in the interval 300$350 \mathrm{~nm}$ [19] and 315-360 nm with maximum between 315 and $330 \mathrm{~nm}$ [47]. This interval could undergo shifts up to 335-360 in presence of a photostabilizer [47] or for the highest conversion degree of oxidation [19]. This later finding can be connected with relevancy to the fast-decomposing fraction of hydroperoxides ascribed to peracids by Gijsman [48]. However, these results corroborate the validity of the present approach (and so the mode of calculation of criterion $J$ ) at least during the induction period up to moderate conversion degrees of oxidation.
Theoretically, both hydroperoxides and ketones may initiate oxidation and should be taken into account. Yet, since hydroperoxides and ketones have a rather similar absorption cross section, functions dJ and activation spectra are almost homothetic
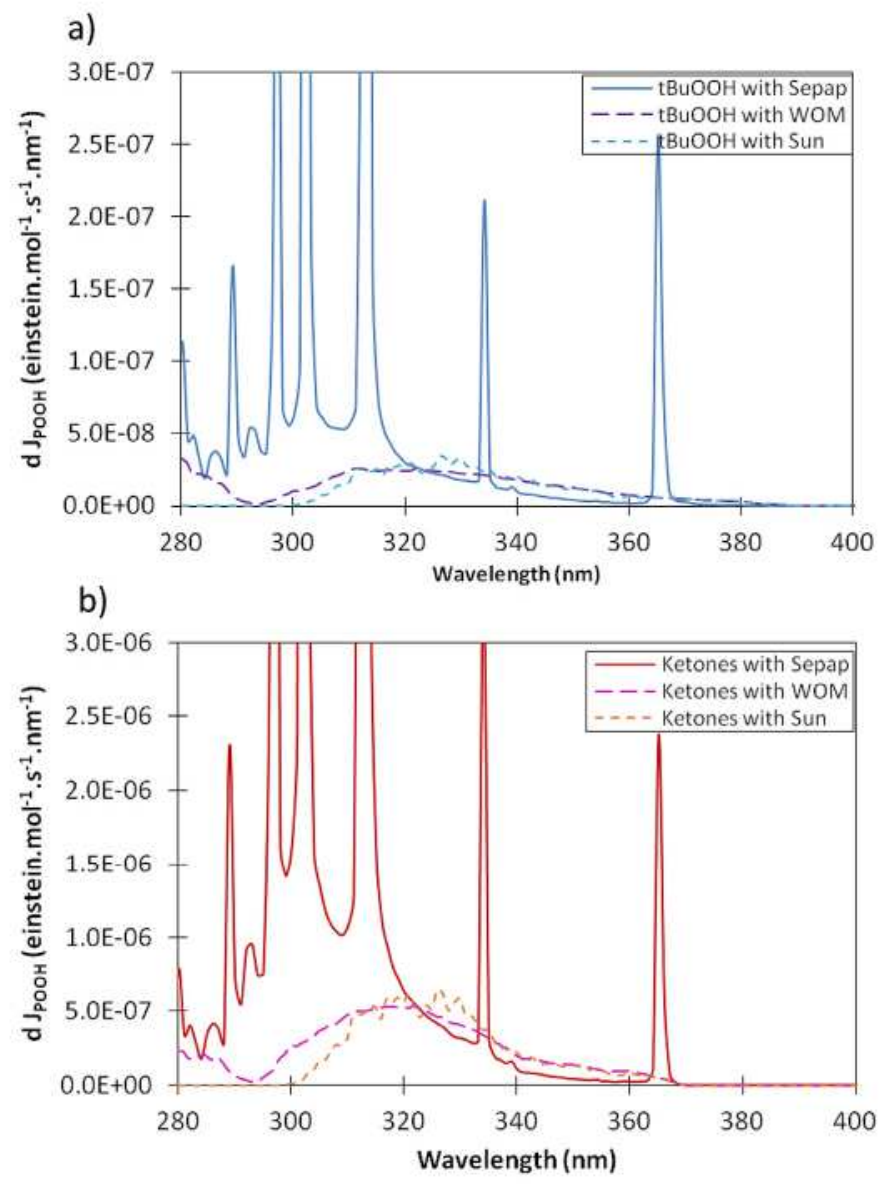

Fig. 4. Plot of the overlap function between the spectra of various UV light sources and the absorption spectra of hydroperoxides (a) and ketones (b). 
comparing both species. One can thus consider a unique initiating species, in this case hydroperoxides, instead of a linear combination of both contributions.

Thus, overlap functions for both hydroperoxides and ketones were calculated for each aging condition (SEPAP and WOM). Complementary data were also extracted from the literature and underwent a similar treatment. All the results are reported in Table 1 . To characterize the oxidation behavior, induction time was considered as the relevant indicator, in a first approach, and was determined by intercepting the slope of the maximal oxidation rate with the abscissa axis.

\subsection{Interpretation according to an empirical Schwarzschild's law}

As reported in introduction, reciprocity laws are commonly used to describe the effect of light intensity on hydrocarbon polymers using empirical parameters. As reviewed by Martin et al. [15], the dependence is not always with the reciprocal of the irradiance. Indeed, the law exponent can deviate from its default value of -1 up to values of -0.7 , according to a so-called Schwarzschild's law. Besides, it has been shown as more relevant to replace the irradiance by the overlap function $J$, basing on the comprehension of initiation processes. To correct the effect of temperature in such a photothermal aging, the induction time is empirically supposed to obey an Arrhenius law, as kinetically determined for the maximal oxidation rate [1]. Similar approaches were already proposed to correlate failure criteria with temperature and light exposure parameters, but with the irradiance as key variable instead of the proposed $J$ overlap criterion $[28,49,50]$. Our improvements lead to the following empirical relationship:

$$
t_{\text {ind }}=K J^{\gamma} \exp \left(-\frac{\mathrm{Ea}_{\text {ind }}}{R T}\right)
$$

Assuming that this law is fulfilled, the activation energy $\mathrm{Ea}_{\text {ind }}$ can be determined by regression from a factorial testing matrix (surface response for different couples of light intensity and temperature) in SEPAP. Using a mean squares minimization criterion, the activation energy Eaind is found to be equal to $27 \mathrm{~kJ} \mathrm{~mol}^{-1}$. This

Table 1

Dependence of the oxidation induction times (OIT) with exposure parameters.

\begin{tabular}{|c|c|c|c|c|c|c|c|}
\hline \multicolumn{5}{|c|}{ Exposure conditions } & \multicolumn{3}{|c|}{ Induction times } \\
\hline $\mathrm{T}\left({ }^{\circ} \mathrm{C}\right)$ & Light source & $\begin{array}{l}\text { Irradiance }\left(\mathrm{W} \mathrm{m} \mathrm{m}^{-2}\right)^{\mathrm{a}} \\
\text { between } 300 \\
\text { and } 400 \mathrm{~nm}\end{array}$ & $\begin{array}{l}\text { Overlap with } \\
\text { hydroperoxides } \\
\left(\text { Einstein } \mathrm{mol}^{-1} \mathrm{~s}^{-1} \text { ) }\right.\end{array}$ & $\begin{array}{l}\text { Overlap with ketones } \\
\text { (Einstein } \mathrm{mol}^{-1} \mathrm{~s}^{-1} \text { ) }\end{array}$ & $\begin{array}{l}\text { OIT } \\
\text { (in hours) }^{\mathrm{b}}\end{array}$ & $\begin{array}{l}\text { OrT calculated at } \\
\left.60^{\circ} \mathrm{C} \text { (in hours }\right)^{\mathrm{c}}\end{array}$ & References \\
\hline 45 & Xenon lamp & 35 & $9.45 \mathrm{E}-07$ & $1.47 \mathrm{E}-05$ & 83.1 & 55.0 & [53] \\
\hline 25 & UVA-351 & 82 & $2.84 \mathrm{E}-06$ & $4.75 E-05$ & 33.2 & 11.9 & [55] \\
\hline 25 & UVA-351 & 163 & $5.66 \mathrm{E}-06$ & $9.47 \mathrm{E}-05$ & 19.8 & 7.1 & [55] \\
\hline 25 & UVA-351 & 325 & $1.13 \mathrm{E}-05$ & $1.89 \mathrm{E}-04$ & 0.8 & 0.3 & [55] \\
\hline 21 & Sunlight. Shanghai & 3.0 & $8.92 \mathrm{E}-08$ & $1.51 \mathrm{E}-06$ & 1170.6 & 365.4 & [55] \\
\hline 60 & UVA Philips TL 40 W/05 Lamp & 68 & $1.11 \mathrm{E}-07$ & $1.78 \mathrm{E}-06$ & 16.6 & 16.6 & [54] \\
\hline 40 & UVA Philips TLK 40 W/05 Lamp & 6 & $1.45 \mathrm{E}-07$ & $2.31 \mathrm{E}-06$ & 823.1 & 471.2 & [1] \\
\hline 55 & UVA Philips TLK 40 W/05 Lamp & 6 & $1.45 \mathrm{E}-07$ & $2.31 \mathrm{E}-06$ & 455.2 & 398.5 & [1] \\
\hline 70 & UVA Philips TLK 40 W/05 Lamp & 6 & $1.45 \mathrm{E}-07$ & $2.31 \mathrm{E}-06$ & 196.6 & 253.5 & [1] \\
\hline 45 & Xenon lamp with $\lambda>266 \mathrm{~nm}$ & 48 & $1.13 \mathrm{E}-06$ & $1.77 \mathrm{E}-05$ & 48.4 & 32.0 & [19] \\
\hline 45 & Xenon lamp with $\lambda>289 \mathrm{~nm}$ & 42 & $7.87 \mathrm{E}-07$ & $1.20 \mathrm{E}-05$ & 51.5 & 34.1 & [19] \\
\hline 45 & Xenon lamp with $\lambda>327 \mathrm{~nm}$ filtered & 34 & $2.71 \mathrm{E}-07$ & $2.76 \mathrm{E}-06$ & 64.9 & 43.0 & [19] \\
\hline 45 & Xenon lamp with $\lambda>346 \mathrm{~nm}$ filtered & 28 & $1.13 \mathrm{E}-07$ & $7.24 \mathrm{E}-07$ & 98.0 & 64.9 & [19] \\
\hline 45 & Xenon lamp with $\lambda>366 \mathrm{~nm}$ filtered & 14 & $2.39 \mathrm{E}-08$ & $3.58 \mathrm{E}-08$ & 131.6 & 87.2 & [19] \\
\hline 45 & Xenon lamp with $\lambda>378 \mathrm{~nm}$ filtered & 6.5 & $6.17 \mathrm{E}-9$ & $8.56 \mathrm{E}-9$ & 138.6 & 91.8 & [19] \\
\hline 45 & Xenon lamp with $\lambda>395 \mathrm{~nm}$ filtered & 1.5 & $7.64 \mathrm{E}-10$ & $4.04 \mathrm{E}-9$ & 139.6 & 92.5 & [19] \\
\hline 45 & Xenon lamp with $\lambda>430 \mathrm{~nm}$ filtered & 0.0 & $0.00 \mathrm{E}+00$ & $0.00 \mathrm{E}+00$ & 139.6 & 92.5 & [19] \\
\hline 60 & SEPAP $14 / 24$ & 23 & $2.88 \mathrm{E}-06$ & 4.27E-05 & 175.7 & 175.7 & [11] \\
\hline 60 & SEPAP $14 / 24$ & 37 & $4.68 \mathrm{E}-06$ & $6.95 \mathrm{E}-05$ & 107.1 & 107.1 & [11] \\
\hline 60 & SEPAP $12 / 24,2$ Lamps & 42 & $5.34 \mathrm{E}-06$ & $7.92 \mathrm{E}-05$ & 72.6 & 72.6 & [11] \\
\hline 60 & SEPAP $14 / 24$ & 66 & $8.45 \mathrm{E}-06$ & $1.25 E-04$ & 57.3 & 57.3 & [11] \\
\hline 60 & SEPAP $12 / 24,4$ Lamps & 84 & $1.07 \mathrm{E}-05$ & $1.59 \mathrm{E}-04$ & 53.3 & 53.3 & [11] \\
\hline 60 & SEPAP $12 / 24,4$ Lamps & 84 & $1.07 \mathrm{E}-05$ & $1.59 \mathrm{E}-04$ & 42.7 & 42.7 & [11] \\
\hline 60 & SEPAP $12 / 24,4$ Lamps & 84 & $1.07 \mathrm{E}-05$ & $1.59 \mathrm{E}-04$ & 37.4 & 37.4 & [20] \\
\hline 60 & SEPAP $12 / 24,4$ Lamps & 84 & $1.07 \mathrm{E}-05$ & $1.59 \mathrm{E}-04$ & 36.4 & 36.4 & [52] \\
\hline 60 & SEPAP $14 / 24$ & 86 & $1.10 \mathrm{E}-05$ & $1.64 \mathrm{E}-04$ & 44.4 & 44.4 & [11] \\
\hline 60 & SEPAP $14 / 24$ & 86 & $1.10 \mathrm{E}-05$ & $1.64 \mathrm{E}-04$ & 39.5 & 39.5 & [11] \\
\hline 65 & SEPAP 50/24, 8 Lamps & 265 & $3.39 \mathrm{E}-05$ & $5.03 E-04$ & 24.6 & 28.0 & [20] \\
\hline 60 & SEPAP $14 / 24$ & 86 & $1.10 \mathrm{E}-05$ & $1.64 \mathrm{E}-04$ & 23.3 & 23.3 & [11] \\
\hline 45 & SEPAP 12/24, 2 Lamps & 38 & $4.92 \mathrm{E}-06$ & $7.30 \mathrm{E}-05$ & 31.9 & 21.1 & This work \\
\hline 45 & SEPAP $12 / 24,4$ Lamps & 84 & $1.07 \mathrm{E}-05$ & $1.59 \mathrm{E}-04$ & 19.1 & 12.7 & This work \\
\hline 60 & SEPAP $12 / 24,2$ Lamps & 38 & $4.92 \mathrm{E}-06$ & $7.30 \mathrm{E}-05$ & 24.1 & 24.1 & This work \\
\hline 60 & SEPAP 12/24, 4 Lamps & 84 & $1.07 \mathrm{E}-05$ & $1.59 \mathrm{E}-04$ & 16.5 & 16.5 & This work \\
\hline 60 & SEPAP 50/24, 6 Lamps & 198 & $2.54 \mathrm{E}-05$ & $3.76 \mathrm{E}-04$ & 5.2 & 5.2 & This work \\
\hline 60 & SEPAP 50/24, 8 Lamps & 265 & $3.39 \mathrm{E}-05$ & $5.03 E-04$ & 14.8 & 14.8 & This work ${ }^{d}$ \\
\hline 80 & SEPAP $12 / 24,2$ Lamps & 38 & $4.92 \mathrm{E}-06$ & $7.30 \mathrm{E}-05$ & 14.0 & 22.9 & This work \\
\hline 80 & SEPAP $12 / 24,4$ Lamps & 84 & $1.07 \mathrm{E}-05$ & $1.59 \mathrm{E}-04$ & 9.5 & 15.5 & This work \\
\hline 80 & SEPAP 50/24, 6 Lamps & 198 & $2.54 \mathrm{E}-05$ & $3.76 \mathrm{E}-04$ & 2.8 & 4.5 & This work \\
\hline 80 & SEPAP 50/24, 8 Lamps & 265 & $3.39 \mathrm{E}-05$ & $5.03 E-04$ & 2.8 & 4.6 & This work \\
\hline 64 & Xenon lamp & 55 & $1.45 \mathrm{E}-06$ & $2.25 E-05$ & 56.2 & 62.3 & This work \\
\hline
\end{tabular}

\footnotetext{
a Irradiances have been calculated in the interval $300-400 \mathrm{~nm}$ by convention.

b Induction times from this work and literature have been calculated using the same method from native points.

c Induction times at $60^{\circ} \mathrm{C}$ have been calculated from equation (6) to plot the master curve.

d This condition has been dismissed in applying the analytical models presumably because of an unsuitable control of the temperature.
} 
activation energy is higher than the value of $15 \mathrm{~kJ} \mathrm{~mol}^{-1}$ found by Balaban for aPP [9], but in agreement with an estimation of 25$50 \mathrm{~kJ} \mathrm{~mol}^{-1}$ [1] made from the data of Mayo [51].

By using equation (6) with the determined activation energy, a kind of master curve can be defined at a given temperature from data obtained at various temperatures. The induction times were then calculated at $60^{\circ} \mathrm{C}$ according to equation (6). Their values are reported in Table 1 . The corresponding master curve is depicted in Fig. 5.

Following this approach, the parameters of the Schwarzschild's law have been determined from the induction times obtained in our experiments, i.e. under both SEPAP and WOM exposure, but also from analogous experiments carried out by Gardette and coworkers in SEPAP devices only $[11,20,52]$. The two sets of data showed light dependences with a power of $\gamma=0.86$, and a power of $\gamma=0.77$ respectively (Fig. 5). So, results obtained by Gardette and coworkers gave rather comparable dependence on the light intensity while all tests were performed in SEPAP at the unique temperature of $60{ }^{\circ} \mathrm{C}[11,20,52]$. So, the temperature correction could be considered as valid in the investigated range. The gap of about one decade on pre-exponential factors $\mathrm{K}$ was ascribed to the fact that these previous samples were weakly stabilized, as suggested by the aging test of a purified control sample [11] whose induction time is close to the master curve established from our results.

At this standpoint, it is notable that the introduction of the spectral overlap integral in the Schwarzschild's law enables to describe the oxidative behavior of our iPP in both SEPAP and WOM devices. Various results on presumably free-additive polypropylenes have been also compiled from the literature in order to check this relationship $([1,19,53-55])$. However, it was only possible to confirm the trend because of the high scattering of induction periods, which was attributed to various amounts of structural defaults (such as catalysis residues) or the uncertainty on input data - e.g. sources' emission spectra.

Nonetheless, when decreasing the value of $J$, the induction period seems to reach a plateau which is not modeled by the Schwarzschild's law. This can be connected to the lower activation energy of photothermal oxidation (i.e. $27 \mathrm{~kJ} \mathrm{~mol}^{-1}$ ) in comparison with thermal oxidation (about $100 \mathrm{~kJ} \mathrm{~mol}^{-1}$ ) as observed in this work and literature [56-59] (appendix A). This fact clearly evidences that this empirical law would be only valid in a restricted range of aging conditions whose boundaries remain to be established.

\subsection{Interpretation using a semi-empirical kinetic approach}

\subsubsection{Theory}

Audouin et al. [1] used the closed-loop scheme to determine the expression of the oxidation induction time in the case of the photothermal oxidation of PP, assuming that both thermal and photochemical initiation processes were unimolecular:

$$
t_{\text {ind }}=\frac{C}{\Phi J+k_{1 \mathrm{u}}^{0} \exp \left(\frac{-E_{1 \mathrm{u}}}{R T}\right)}
$$

with $\mathrm{C}$ a universal constant depending upon the monitored chemical species ( $C=3$ for carbonyl species and $C=0.383$ for hydroperoxides),

$\Phi$ the quantum yield, $J$ the spectral overlap integral, $k_{1 u}^{0}$ and $\mathrm{Ea}_{1 \mathrm{u}}$ the preexponential factor and activation energy respectively for a unimolecular thermal initiation.

Actually, this amounts to consider that the photothermal oxidation applies to the case of the thermal oxidation, but taking into account an additional initiation, i.e. the photolysis of a given chromophore. This approach constitutes a foundation for the general kinetic approach initiated by Tobolsky and Mesrobian $[60,61]$. The induction period before oxidation $t_{\text {ind }}$ would thus result from the competition of two modes of initiation: the photolysis and thermolysis of the relevant photosensitive species (namely hydroperoxides in the closed-loop scheme) [62].

It is noteworthy that a correction is implemented here as compared with the original model [1]: the spectral overlap integral (i.e. the amount of absorbed quanta) is substituted to the UV-light intensity measured by actinometry. Thereby, the absorbed intensity is normalized by the concentration in the considered photosensitive species (e.g. hydroperoxide or ketone). In this way, the photoinitiation term is effectively homogeneous to a kinetic rate

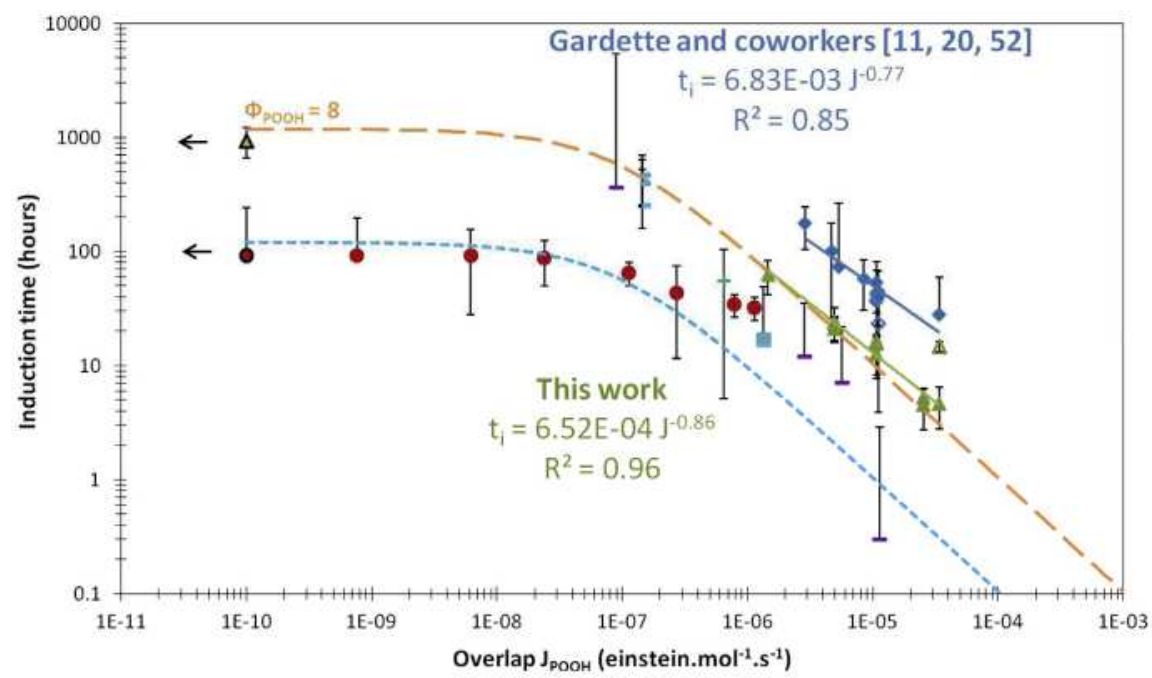

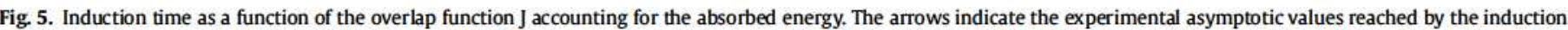

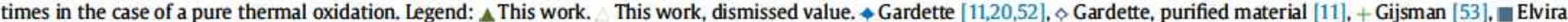

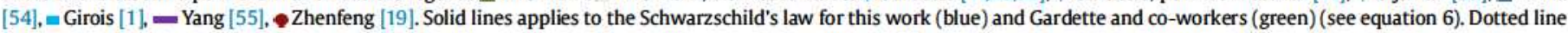
apply to the kinetic model (equation 8) with $\lambda=1$ (in orange) and $\lambda=10$ (in cyan) (colors are available online). 
constant for a unimolecular reaction $\left(\mathrm{s}^{-1}\right)$. This is the reason why both the thermolysis and photolysis of hydroperoxides are assumed to be unimolecular. Otherwise, the analytical kinetic treatment would be significantly complexified. The unimolecularity is commonly accepted for the photochemical initiation (see Ref. [23] for instance). It is also acceptable for thermal initiation since, in this case, the induction time only obeys a reciprocal dependence with the initiation rate constant (see Ref. [59] for instance).

It is also important to precise that the kinetic law would be anyway applicable for modeling the induction times of both hydroperoxides and ketones, by only changing the value of the constant C. Indeed, the kinetic law is independent of the specificity of their accumulation mode in the polymer matrix. It only differs by the value of $\mathrm{C}$ because the formations of both species are finally correlated, the latter resulting from the decomposition of the former (the detailed kinetic treatment of the closed-loop mechanistic scheme can be found elsewhere [62]).

The determination of the model's parameters is operated stepwise. First, the apparent Arrhenius parameters for $k_{1 \mathrm{u}}$ were determined from thermal oxidation experiments (monitoring of carbonyl species). Their values are: $k_{1 \mathrm{u}}^{0}=2.45 \times 10^{-9} \mathrm{~s}^{-1}$ and $\mathrm{Ea}_{1 \mathrm{u}}=99.2 \mathrm{~kJ} \mathrm{~mol}^{-1}$ (appendix A).

Then, the quantum yields were determined from the regression straight-lines of Fig. 6 . They are found equal to $\Phi_{\mathrm{POOH}}=8.5 \pm 1.7$ and $\Phi_{\mathrm{C}=0}=0.57 \pm 0.1$ mol Einstein $^{-1}$ for hydroperoxides and ketones respectively.

Correlation coefficients are equal for both chemical species, presumably due to their similar wavelength sensitivities as shown in Fig. 4.

\subsubsection{Comparison of both analytical models}

The light dependence described by equation (7) has been plotted in Fig. 5 in order to compare both the Schwarzschild's and the kinetic models. The lower coefficient of correlation (equal to 0.86 ) indicates that the kinetic model does not provide a better fit of our experimental data in photothermal aging (the reverse is even observed). This is not surprising given the simplifying assumptions of the model, namely the unicity of the initiation species (hydroperoxides) and its unimolecular thermal and photochemical decompositions.

Instead, it can be considered that the kinetic model offers a "better" description of the oxidation behavior as far as it is valid whatever the exposure conditions (in terms of temperature and UV-light intensity). More particularly, when the light intensity

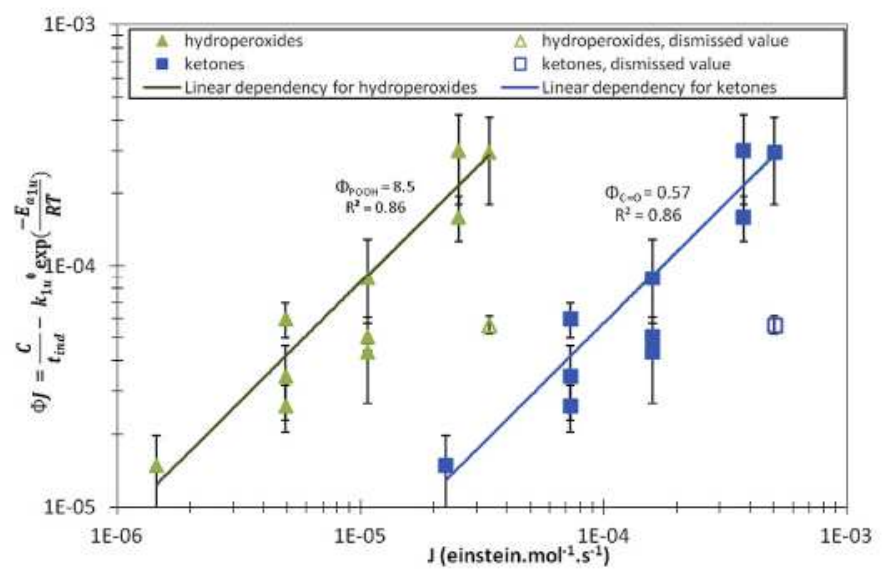

Fig. 6. Kinetic correlation between the photolysis initiation rate and the overlap function $J$. The slope of the curve corresponds to the quantum yield. tends towards 0 , it generates a plateau describing the thermal oxidation regime, whose existence is attested by the asymptotic experimental value indicated by an arrow. This trend is particularly well evidenced by the results obtained by Zhenfeng et al. [19] for very low radiation intensities despite the vertical shift of the trend curve. This shift would be presumably due to the presence of a higher content of impurities in the PP samples such as catalysis residues or prodegradant additives. By assuming that the kinetic parameters $\mathrm{k}_{1 \mathrm{u}}$ and $\Phi \mathrm{J}$ are proportional to the concentration of impurities, the equation (7) becomes:

$$
t_{\text {ind }}=\frac{1}{\lambda} \frac{C}{\Phi J+k_{1 \mathrm{u}}^{0} \exp \left(\frac{-E a_{1 \mathrm{u}}}{R T}\right)}
$$

It is thus possible to apply the kinetic model to the experimental data of Zhenfeng [19] by adjusting the parameter $\lambda$ accounting for the material variability. This latter kinetic trend is depicted in Fig. 5. As for radiothermal aging, the polymer lifetime results here from the competition between two different initiation reactions respectively induced by temperature (intrinsic mode) and radiation (extrinsic mode) $[63,64]$.

\subsubsection{A powerful investigation tool for the competition of light and thermal effects}

Therefore, the previous kinetic model enables to determine the ranges of relative predominance of UV-light and temperature to initiate oxidation in unstabilized PP. Different combinations of exposure conditions, in terms of light - as described by the spectral overlap integral $J$ - and temperature, apply to a same balance between both sources of initiation. These equivalent combinations are given through the equation (8), for a ratio $\theta$ between both terms fixed from 0 to $+\infty$ :

$$
\Phi J=\theta k_{1 \mathrm{u}}^{0} \exp \left(\frac{-E a_{1 \mathrm{u}}}{R T}\right)
$$

According to the kinetic model (equation (7)), the induction period would be proportional to the reciprocal rate of initiation (either by thermolysis or photolysis). Thus, aging by thermal and photochemical oxidation can be considered as equivalent in terms of mechanisms, at least those concerning primary processes (those determining the induction period). It is thus possible to plot the curves of iso-lifetime. Theoretically, this model would also suggest that the chemistries of thermal and photochemical oxidation would be identical, i.e. that a same conversion degree induces the same alteration level of the polymer properties. If this statement was always fulfilled, curves of iso-lifetime would be analogous to curves of iso-damages.

However, this is not exactly the case and it is generally recommended to maintain the balance between both kinds of initiation processes (thermal and photochemical). In such conditions, an accelerated aging test will be considered as representative of natural aging, which means situated on a same representativity curve. All the exposure conditions which apply to a same balance between both kinds of initiation (i.e. representative one another) and plot a so-called "representativity curve" can be obtained by solving equation ( 8 ) for a given $\theta$ value.

These operations allow to build an abacus for the relative predominance of UV-light and temperature on the photothermal aging of unstabilized PP as depicted in Fig. 7. Domains of predominance are directly obtained from equation (9) with the corresponding inequalities. To draw the boundaries, the photochemical and thermal initiations were alternatively considered as predominant so long as the effect of the minor initiation source on the induction time would be lower than $10 \%$. 


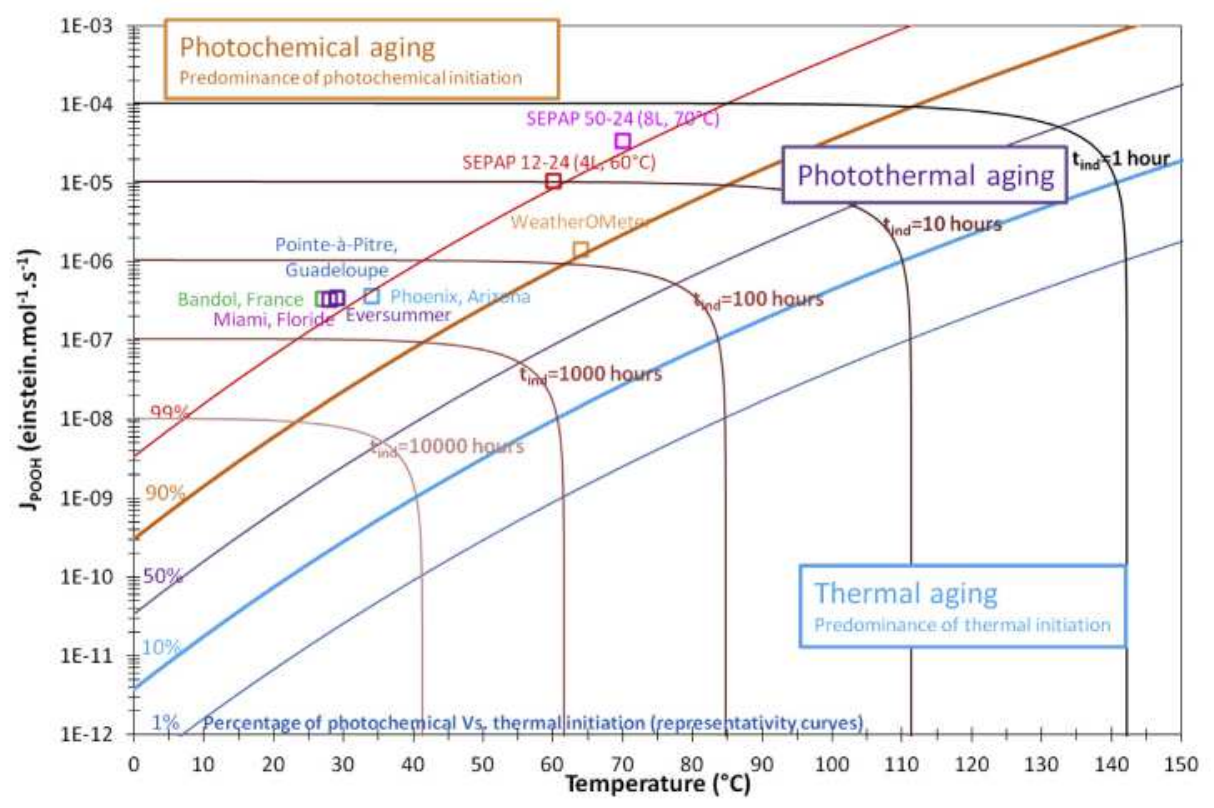

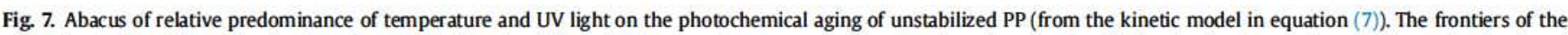

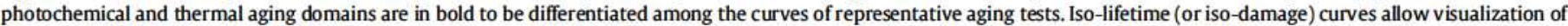
the acceleration factor between two aging methods. Symbols indicate exposure conditions in reference testing methods or weathering sites.

The abacus thus allows to evaluate how relevant are the exposure conditions used in a given test method, in terms of light and temperature. It includes all the experimental conditions of the tested methods as well as those of common validation ones, both in artificial and outdoor weathering. For this latter, submitted to seasonal variations, average values were estimated from the cumulated light dosage for different reference weathering sites (there is here a small approximation). According to the representativity curve applying to $99 \%$ of photochemical initiation, the SEPAP 12-24 method would be more representative of natural aging conditions than the WOM method, which applies to "only" $90 \%$ of photochemical initiation. Practically, both SEPAP and WOM methods are acceptable because they both belong to the domain of predominance of photochemical initiation according to the chosen boundaries.

When moving on the representativity curve, it is possible to visualize the acceleration factor by using the iso-lifetime curves. The lifetime in real aging conditions was thus calculated to be about $290 \pm 15 \mathrm{~h}$ with equation (7). The acceleration factor would thus be of $18 \pm 1$ in respect to the experimental value obtained though an accelerated test in a SEPAP 12-24 device, and $29 \pm 2$ in respect to the value returned by the model (the gap applies to the error of fit). These values are of the same order of magnitude as those experimentally determined by Arnaud et al. for unstabilized PP, which are generally ranged between 8 and 22 [65].

\subsubsection{The heuristic value of the kinetic model}

The main issue in the proposed kinetic model consists in the unrealistic value for the quantum yield of hydroperoxide photolysis. This one is found equal to more than 8 , whereas it should not theoretically worth more than unity - i.e. $100 \%$ - in the case of elementary initiation reactions. However, this finding can be compared to the values determined from photolysis experiments of PP hydroperoxides in inert conditions. Thus, Carlsson and Wiles determined apparent quantum yields up to 4.8 ( $4 \pm 1$ on average) $[30,31]$ and a value of about 4.2 was calculated from experiments of Commereuc et al. [66]. Eventually, the experimental quantum yield of $\Phi_{\mathrm{POOH}}=4$ must be considered as the target value since obtained by photolysis and its excessive value would be due to "internal effects", i.e. specific mechanisms induced by hydroperoxide decomposition itself (and thus strongly correlated) or unsuitable hypothesis about its photosensitive features. The possible underestimation of the spectral cross sections for photosensitive species has been already envisaged by Carlsson, whose data have been reused here. It is however unimportant on the results since spectral cross sections of various hydroperoxides or ketones have been shown to be homothetic depending on model compounds (Figs. 2 and 3).

However, the factor 2 between the model's and the target values could result from unsuitable simplifying hypotheses used for determining analytical equation (7):

(i) The hypothesis of unimolecular thermal initiation, while decomposition of hydroperoxides was shown to be mostly bimolecular at these temperatures [67]:

(ii) The hypothesis of a unique chromophoric species.

It is noteworthy that the model is theoretically designed for describing the UV-light initiation on a single photosensitive species. Practically, initiation is assumed to come from mostly hydroperoxide photolysis because of the high cleavability of the corresponding $\mathrm{O}-\mathrm{O}$ bond [31]. Theoretically, it would be possible to consider several sources of photo-initiation provided that the balance reactions are of a similar form. Therefore, the equation (7) becomes:

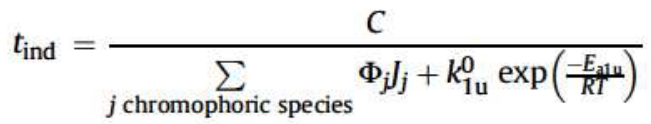

This condition is fulfilled with the two photosensitive species under investigation, namely hydroperoxides (or even alkyl peroxides) and ketones since:

$\mathrm{POOH} \rightarrow 2 \mathrm{P}^{\circ}+$ inactive products 
$\mathrm{P}=\mathrm{O} \rightarrow 2 \mathrm{P}^{\circ}+$ inactive products

Moreover, since the spectral sensitivity of hydroperoxides and ketones are almost homothetic, equation (10) can be rewritten as:

$$
t_{\text {ind }}=\frac{C}{(1+\beta) \Phi_{\mathrm{POOH}} J+k_{1 \mathrm{u}}^{0} \exp \left(\frac{-E_{\text {aul }}}{R T}\right)}
$$

Finally, the overall quantum yield, which is determined experimentally by an inverse method (see Fig. 7), would be a composite value accounting for various photochemical initiating species.

Otherwise, explanations would lie in the higher complexity of the involved reactions and phenomena:

(i) Potential energy transfer reactions via keto-hydroperoxides complexes - or exciplexes - to benefit from both high quantum yield (cleavable bonds) of hydroperoxides and high cross section of ketones (powerful chromophores) [68-71].

(ii) Involvement of other photochemical reactions, not belonging to the initiation step, would have dramatic effects on PP lifetime.

\section{Conclusion}

First of all, the spectral overlap integral $J$ was proposed as a relevant criterion to describe the effect of the spectral distribution of light, and so, to establish a heuristic correlation between the common light sources in artificial and outdoor weathering. This quantity, derived from the quantum theory (i.e. band gap theory in electronics), applies to the energy absorbed by the photosensitive species whose photolysis will produce radicals and initiate photodegradation. This was checked to be consistent with the literature activation spectra defined as the light wavelength domain which will be efficient for generating damages. The criterion $J$ is defined in such a way that it is independent of the specificity of the chromophores accumulation mode in the polymer matrix. Therefore, it can be introduced with relevancy in analytical models (namely the Schwarzschild's law and kinetic model) in order to describe the impact of exposure factors (temperature and UV-light) on the induction period whatever the light source under consideration (including xenon and medium pressure mercury lamps).

Secondly, this study enables to apprehend the limitations of both types of analytic approaches in order to describe the competitive effects of light and temperature. While the Schwarzschild's law was slightly better for modeling the results in photothermal aging, only the kinetic model would be valid in the whole light intensity range under study (including the pure thermal oxidation). In fact, the kinetic model is particularly indicated for describing the competition between UV-light and temperature on the initiation of oxidation (at least, in terms of primary processes). This second model thus allows determination of the restricted domain where the Schwarzschild's law is presumably valid, i.e. the domain where photochemical initiation is predominant. It also constitutes a powerful tool to compare different aging testing methods in accelerated and natural exposure conditions. It turns out that, as expected, the Xenon lamp provides a better description of the effect of the light wavelength on degradation, but it is finally off topic provided that this effect is properly described (which is the case through the spectral overlap integral). What matters is the suitable description of the competitive effects of UV-light and temperature.

Theoretically, the kinetic model states that temperature and UVlight would have analogous impact on the PP degradation. This approximation, coming from simplifying assumptions such as the unimolecular decomposition of hydroperoxides, the unicity of initiating species (neglecting ketones) or the neglect of the small differences in chemistry, leads to a questionable value for the quantum yield. Indeed, this latter is twice higher than the expected value although of the right order of magnitude. For these reasons, it is recommended to position the accelerated testing methods in representative conditions of natural weathering (i.e. for the same ratio of photochemical initiation). Clearly, the kinetic model provides interesting trends for describing the effects of the exposure conditions on the induction period but another important oxidation indicator, the maximal oxidation rate, has been left aside. It is also noteworthy that the kinetic model was only established for unstabilized PP and parameters would probably differ for stabilized materials (as established for the Schwarzschild's law in introduction). Finally, neither its accuracy nor its physical substantiations lead to recommend this analytical model for lifetime prediction.

Its translation into a numerical form will allow us to eradicate all the simplifying hypotheses and check the validity of some complex phenomena (such as the multiple initiating species, termolecular processes or energy transfers) as well as the interaction with additional components, particularly stabilizers.

\section{Acknowledgments}

Dr. Narcisse Siampiringue from the Centre National d'Evaluation de Photoprotection (Clermont-Ferrand, France) is greatly acknowledged for carrying out radiations exposure experiments.

\section{Appendix A. Thermal aging results}

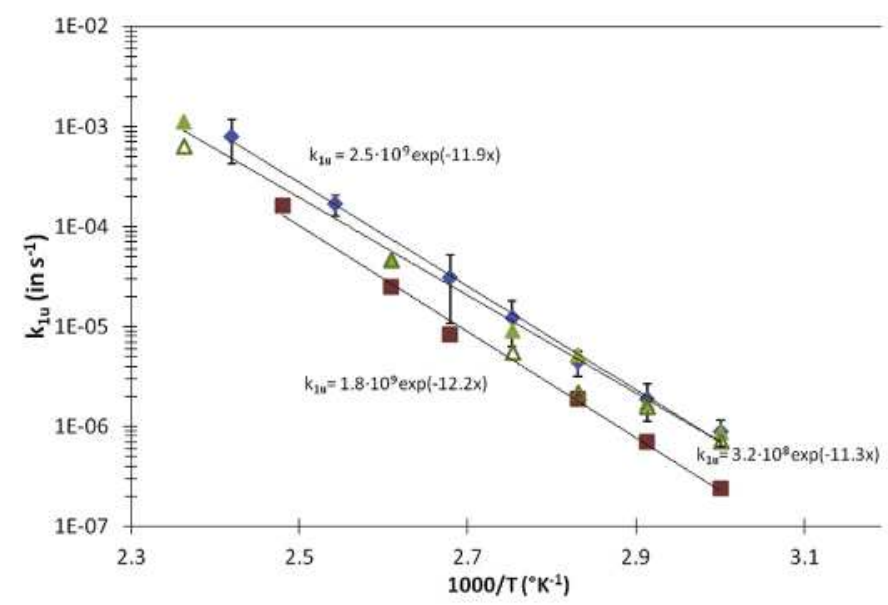

Figure A.1. Arrhenius graphs for the thermal initiation rate constant for: $\$$ This work. - Richaud et al. [57], $\triangle$ Achimsky [58], Achimsky et al. [56]. The value of pseudounimolecular kinetic rate constants are determined from the induction times using $t_{\text {ind }}=3 / k_{1 \mathrm{u}}$

Table A.1

Arrhenius parameters of the thermal initiation rate constant in thermal oxidation.

\begin{tabular}{lcl}
\hline & $\mathrm{Ea}_{1 \mathrm{u}}\left(\mathrm{kJ} \mathrm{mol}^{-1}\right)$ & $k_{1 \mathrm{u}}^{0}\left(\mathrm{~s}^{-1}\right)$ \\
\hline This work & $99.2 \pm 6.5$ & $(2.45 \pm 5.27) 10^{9}$ \\
Achimsky $[56,58]$ & $93.5 \pm 9.9$ & $(3.16 \pm 10.30) 10^{8}$ \\
Richaud [57] & $101.2 \pm 13.5$ & $(1.8 \pm 8.0) 10^{9}$ \\
\hline
\end{tabular}

\section{References}

[1] Audouin L, Girois S, Achimsky L, Verdu J. Effect of temperature on the photooxidation of polypropylene films. Polym Degrad Stab 1998;60:137-43.

[2] Karpukhin ON, Slobodetskaya EM. Photooxidation of polyolefins and their light stability. J Polym Sci Polym Chem Ed 1979;17:3687-94. 
[3] Chin JW, Nguyen T, Gu X, Byrd E, Martin J. Accelerated UV weathering of polymeric systems: recent innovations and new perspectives. JCT CoatingsTech 2006;3:20-6.

[4] Christensen PA, Dilks A, Egerton TA, Temperley J. Infrared spectroscopic evaluation of the photodegradation of paint: part II: the effect of UV intensity \& wavelength on the degradation of acrylic films pigmented with titanium dioxide. J Mater Sci 2000;35:5353-8.

[5] Diepens M, Gijsman P. Influence of light intensity on the photodegradation of bisphenol A polycarbonate. Polym Degrad Stab 2009;94:34-8.

[6] Jorgensen G, Bingham C, King D, Lewandowski A, Netter ], Terwilliger K, et al. Use of uniformly distributed concentrated sunlight for highly accelerated testing of coatingsin Service life prediction. American Chemical Society; 2001. pp. 100-18.

[7] Pickett JE, Gibson DA, Gardner MM. Effects of irradiation conditions on the weathering of engineering thermoplastics. Polym Degrad Stab 2008;93:1597606.

[8] Braun D, Kull S. Photoabbau von PVC-folien. I. Einfluß von bestrahlungsstärke und temperature. Die Angew Makromol Chem 1980;85:79-90.

[9] Balabán L, Majer J, Vesely K. Photooxidative degradation of polypropylene. J Polym Sci Part C Polym Symp 1969;22:1059-71.

[10] Karpukhin ON, Slobodetskaya YM. The photo-oxidation of polypropylene and the changes in its physico-mechanical characteristics. Polym Sci USSR 1976;18:3084-90.

[11] Philippart JL, Sinturel C. Gardette. Influence of light intensity on the photooxidation of polypropylene. Polym Degrad Stab 1997:58:261-8.

[12] Vink P, Van Veen T]. The mechanism of u.v. stabilization of polypropylene films by 2-hydroxy-4-octyloxybenzophenone. Eur Polym J 1978;14:533-7.

[13] Kollmann TM, Wood DGM. Effects of variations in light intensity on the photooxidation of polypropylene. Polym Eng Sci 1980;20:684-7.

[14] Bigger SW, Scheirs J, Delatycki O. Effect of light intensity on the photooxidation kinetics of high-density polyethylene. J Polym Sci Part Polym Chem 1992;30:2277-80.

[15] Martin JW, Chin JW, Nguyen T. Reciprocity law experiments in polymeric photodegradation: a critical review. Prog Org Coatings 2003;47:292-311.

[16] Vink P. Photooxidation of polypropylene. J Appl Polym Sci Appl Polym Symposium 1979;35:265-73.

[17] Searle ND. Activation spectra of polymers and their application to stabilization and stability testing. In: Hamid $\mathrm{SH}$, editor. Handbook of polymer degradation. 2nd ed. New York: Marcel Dekker, Inc; 2000. pp. 605-43.

[18] Andrady AL. Wavelength sensitivity in polymer photodegradation. Adv Polym Sci 1997:46-94.

[19] Zhenfeng Z, Xingzhou H, Zubo L. Wavelength sensitivity of photooxidation of polypropylene. Polym Degrad Stab 1996;51:93-7.

[20] Philippart Jean-Louis, Sinturel Christophe, Amaud René, Gardette Jean-Luc. Influence of the exposure parameters on the mechanism of photooxidation of polypropylene. Polym Degrad Stab 1999;64:213-25.

[21] Geburtig A, Wachtendorf V. Determination of the spectral sensitivity and temperature dependence of polypropylene crack formation caused by UVirradiation. Polym Degrad Stab 95:2118-23.

[22] Ranby B, R JF. Photodegradation, photo-oxidation, and photostabilization of polymers principles and applications; 1975.

[23] Calvert JG, Pitts Jr JN. Chapter 5 (Photochemistry of the polyatomic molecules). 1966, p. 443

[24] Martin JW. Quantitative characterization of spectral ultraviolet radiationinduced photodegradation in coating systems exposed in the laboratory and the field. Prog Org Coatings 1993:23:49-70.

[25] Martin JW, Lechner JA, Varner RN. Quantitative characterization of photodegradation effects of polymeric materials exposed in weathering environment. In: Ketola WD, Grossman D, editors. Accelerated and outdoor durability testing of organic materials 1994. pp. 27-51.

[26] Bauer DR. Interpreting weathering acceleration factors for automotive coatings using exposure models. Polym Degrad Stab 2000;69:307-16.

[27] Bauer DR. Global exposure models for automotive coating photo-oxidation. Polym Degrad Stab 2000;69:297-306.

[28] Jorgensen G]. A phenomenological approach to obtaining correlation between accelerated and outdoor exposure test results for organic materials. West Conshohocken, PA; 2003.

[29] Carlsson DJ, Wiles DM. The photodegradation of polypropylene films. II photolysis of ketonic oxidation products. Macromolecules 1969:2:587-97.

[30] Carlsson DJ, Wiles DM. The photooxidative degradation of polypropylene. Part I. photooxidation and photoinitiation processes 1976;14:65-106.

[31] Carlsson DJ, Wiles DM. The photodegradation of polypropylene films. III Photolysis of polypropylene hydroperoxydes. Macromolecules 1969;2:597606.

[32] Martin JT, Norrish RGW. The photochemical decomposition of tert-butyl hydroperoxyde. Proc R Soc Lond Ser Math Phys Sci 1953;220:322-39.

[33] Jorand Fo, Kerhoas L, Heiss A, Einhorn J, Sahetchian K. Determination of the ultra violet absorption cross section of hexyl-ketohydroperoxides in solution in acetonitrile. J Photochem Photobiol Chem 2000;134:119-25.

[34] Blitz Mark A, Heard Dwayne E, Pilling Michael J. Wavelength dependent photodissociation of $\mathrm{CH}_{3} \mathrm{OOH}$ quantum yields for $\mathrm{CH}_{3} \mathrm{O}$ and $\mathrm{OH}$, and measurement of the $\mathrm{OH}+\mathrm{CH}_{3} \mathrm{OOH}$ rate coefficient. J Photochem Photobiol Chem 2005;176:107-13.

[35] Matthews J, Sinha A, Francisco JS. The importance of weak absorption features in promoting tropospheric radical production. Proc Natl Acad Sci U S A 2005: 7449 .
[36] Molina MJ, Arguello G. Ultraviolet absorption spectrum of methylhydroperoxide vapor. Geophys Res Lett 1979;6:953-5.

[37] Vaghjiani GL, Ravishankara AR. Photodissociation of $\mathrm{H}_{2} \mathrm{O}_{2}$ and $\mathrm{CH}_{3} \mathrm{OOH}$ at 248 $\mathrm{nm}$ and $298 \mathrm{~K}$ : quantum yields for $\mathrm{OH}, \mathrm{O}\left({ }^{3} \mathrm{P}\right)$ and $\mathrm{H}\left({ }^{2} \mathrm{~S}\right)$. J Chem Phys 1990;92: 996-1003.

[38] Roehl CM, Marka Z, Fry JL, Wennberg PO. Near-UV photolysis cross sections of $\mathrm{CH}_{3} \mathrm{OOH}$ and $\mathrm{HOCH}_{2} \mathrm{OOH}$ determined via action spectroscopy. Atmos Chem Phys Dis 2006;6:11597-620.

[39] Takezaki Y, Miyazaki T, Nakahara N. Photolysis of dimethyl peroxide. J Chem Phys 1956;25:536-42.

[40] Yujing M, Mellouki A. The near-UV absorption cross sections for several ketones. J Photochem Photobiol Chem 2000;134:31-6.

[41] Gierczak T, Burkholder JB, Bauerle S, Ravishankara AR. Photochemistry of acetone under tropospheric conditions. Chem Phys 1998;231:229-44.

[42] Martinez RD, Buitrago AA, Howell NW, Hearn CH, Joens JA. The near U.V. absorption spectra of several aliphatic aldehydes and ketones at $300 \mathrm{~K}$. Atmos Environ A General Top 1992;26:785-92.

[43] Guillet JE, Dhanraj J, Golemba FJ, Hartley GH. Fundamental processes in the photodegradation of polymersin Stabilization of polymers and stabilizer processes. AMERICAN CHEMICAL SOCIETY; 1968, pp. 272-86.

[44] Mowery DM, Assink RA, Derzon DK, Klamo SB, Clough RL, Bernstein R. Solidstate 13C NMR investigation of the oxidative degradation of selectively labeled polypropylene by thermal aging and $\hat{P}^{3}$-irradiation. Macromolecules $2005 ; 38: 5035-46$

[45] Tadic, Jovan, Juranic, Ivan, Moortgat, Geert K. Pressure dependence of the photooxidation of selected carbonyl compounds in air: n-butanal and npentanal, Amsterdam, PAYS-BAS: Elsevier; 2001.

[46] Zhu L, Tang Y, Chen Y, Cronin T. Wavelength-Dependent photolysis of C3-C7 aldehydes in the 280-330 $\mathrm{nm}$ region. Spectrosc Lett 2009;42:467-78.

[47] Andrady AL, Hamid SH, Hu X, Torikai A. Effects of increased solar ultraviolet radiation on materials. J Photochem Photobiol B Biol 1998;46:96-103.

[48] Gijsman P, Kroon M, van Oorschot M. The role of peroxides in the thermooxidative degradation of polypropylene. Polym Degrad Stab 1996;51: 3-13.

[49] Tomiita K. Hardware and software for weathering simulation of polymeric used outdoors. In: Reichert T, editor. 3rd European weathering symposium, Krakow 2007. pp. 221-30.

[50] Tobias PS, Trindade DC. Applied reliability. New York; 1995.

[51] Mayo FR. Relative reactivities in oxidations of polypropylene and polypropylene models. Macromolecules 1978;11:942-6.

[52] Gardette J-L, Sinturel C, Lemaire J. Photooxidation of fire retarded polypropylene. Polym Degrad Stab 1999;64:411-7.

[53] Gijsman P, Meijers G, Vitarelli G. Comparison of the UV-degradation chemistry of polypropylene, polyethylene, polyamide 6 and polybutylene terephthalate. Polym Degrad Stab 1999;65:433-41.

[54] Castejon ML, Tiemblo P, Gomez-Elvira JM. Photo-oxidation of thick isotactic polypropylene films I. Characterisation of the heterogeneous degradation kinetics. Polym Degrad Stab 2000;70:357-64.

[55] Yang X, Ding X. Prediction of outdoor weathering performance of polypropylene filaments by accelerated weathering tests. Geotext Geomembranes 2006;24:103-9.

[56] Achimsky L, Audouin L, Verdu J, Rychly J, Matisova-Rychla L, On a transition at $80^{\circ} \mathrm{C}$ in polypropylene oxidation kinetics. Polym Degrad Stab 1997:58:283-9.

[57] Richaud E, Farcas F, Bartoloméo P, Fayolle B, Audouin L, Verdu J. Effect of oxygen pressure on the oxidation kinetics of unstabilised polypropylene. Polym Degrad Stab 2006;91:398-405.

[58] Achimsky L. Etude cinétique de la thermooxydation du polypropylène. Ph.D thesis. Paris: Université Pierre et Marie-Curie (Paris VI); 1996.

[59] Achimsky L, Audouin L, Verdu J. Kinetic study of the thermal oxidation of polypropylene. Polym Degrad Stab 1997;57:231-40.

[60] Tobolsky AV. Oxidative degradation of polymeric material. Discuss Farad Soc $1947: 2: 384-8$.

[61] Tobolsky AV, Metz DJ, Mesrobian RB. Low temperature autoxidation of hydrocarbons: the phenomenon of maximum rates. J Am Chem Soc 1950;72: $1942-52$.

[62] Audouin L, Achimsky L, Verdu J. Kinetic modelling of low-temperature oxidation of hydrocarbon polymers. In: Hamid SH, editor. Handbook of polymer degradation. 2nd ed. New York: Marcel Dekker; 2000. p. 734

[63] Khelidj N, Colin X, Audouin L, Verdu J. A simplified approach for the lifetime prediction of PE in nuclear environments. Nucl Instr Meth Phys Res Sect B Beam Interact Mater Atoms 2005;236:88-94.

[64] Khelidj N, Colin X, Audouin L, Verdu J, Monchy-Leroy C, Prunier V. Oxidation of polyethylene under irradiation at low temperature and low dose rate. Part II. Low temperature thermal oxidation. Polym Degrad Stab 2006;91: $1598-605$.

[65] Amaud R, Gardette J-L, Lacoste J, Rivaton A. Evolution photochimique des macromolécules organiques naturelles et synthétiques- Photoprotection des matériaux polymères synthétiques. L'Actualité Chim 1994;12/94(7 (suppl.)): 132-210 [In french].

[66] Commereuc S, Vaillant D, Philippart JL, Lacoste J, Lemaire J, Carlsson DJ. Photo and thermal decomposition of iPP hydroperoxides. Polym Degrad Stab $1997: 57: 175-82$

[67] Billingham NC, Then ETH, Kron A. Chemiluminescence from peroxides in polypropylene: II. Luminescence and kinetics of peroxide decomposition. Polym Degrad Stab 1997;55:339-46. 
[68] Geuskens G, Debie F, Kabamba MS, Nedelkos G. New aspects of the photooxidation of polyolefins. Polym Photochem 1984;5:313-31.

[69] Geuskens G, Kabamba MS. Photo-oxidation of polymers-part V: a new chain scission mechanism in polyolefins. Polym Degrad Stab 1982;4:69-76.

[70] Geuskens G, Kabamba MS. Photo-oxidation of polymers: part IX-Additional comments about a new chain scission mechanism in polyolefins. Polym Degrad Stab 1983;5:399-401.
[71] Guillet JE. Studies of energy transfer and molecular mobility in polymer photochemistry. Pure Appl Chem 1977;49:249-58.

[72] Cox RA, Tyndall GS. Rate constants for reactions of $\mathrm{CH}_{3} \mathrm{O}_{2}$ in the gas phase. Chem Phys Lett 1979;65:357-60. 